\title{
In and out of the STEM pipeline - a longitudinal study of a misleading metaphor
}

Lykkegaard, Eva ; Ulriksen, Lars

Published in:

International Journal of Science Education

DOI:

10.1080/09500693.2019.1622054

Publication date:

2019

Document version

Peer reviewed version

Citation for published version (APA):

Lykkegaard, E., \& Ulriksen, L. (2019). In and out of the STEM pipeline - a longitudinal study of a misleading metaphor. International Journal of Science Education, 41(12), 1600-1625.

https://doi.org/10.1080/09500693.2019.1622054 
The accepted version. The original paper is published as:

Lykkegaard, E., \& Ulriksen, L. (2019). In and out of the STEM pipeline

- a longitudinal study of a misleading metaphor. International Journal

of Science Education, 41(12), 1600-1625. doi:

$10.1080 / 09500693.2019 .1622054$

https://www.tandfonline.com/doi/full/10.1080/09500693.2019.1622054 


\section{In and out of the STEM pipeline - a longitudinal study of a misleading metaphor}

\section{Eva Lykkegaard ${ }^{\mathrm{a} *}$ and L. Ulriksen ${ }^{\mathrm{b}}$}

${ }^{a}$ Centre for Science Education, University of Aarhus, Aarhus, Denmark ${ }^{1}$ (Orcid: 00000002-2266-9528); ${ }^{b}$ Department of Science Education, University of Copenhagen, Copenhagen, Denmark (Orcid: 0000-0002-7094-132X)

*Eva Lykkegaard, Campusvej 55, DK-5230 Odense M, Denmark, eval@sdu.dk

\section{Biographical notes}

Eva Lykkegaard is an assistant professor in Educational Science. She is interested in students' educational transitions: educational choice processes, students' participation and integration as they enter new study programmes and students' study success or dropout.

Lars Ulriksen is a professor at the Department of Science Education. He has done research on students' choice of higher education, in particular their choice of STEM, and on how students experience the transition into higher education.

There were no conflicts of interest.

This work was supported by Central Denmark Region

${ }^{1}$ Now Educational Science, Department for the study of Culture, University of Southern Denmark, Odense, Denmark 


\title{
In and out of the STEM pipeline - a longitudinal study of a misleading metaphor
}

\author{
In the discussion on recruitment and retention of students in STEM higher- \\ education programmes, the metaphor of the leaking pipeline is sometimes used, \\ indicating that,
}

as students advance through the educational systems, some of them are lost. This paper follows a cohort of upper-secondary school students with an interest in STEM from 18 months before their completion of upper-secondary school until three years after their completion. Adopting a mixed-methods design, it follows the reflections and interests of the students concerning their choice of higher education, and, in particular, whether they enter a STEM higher-education programme. Only $22 \%$ of the students expressed the same interest during the whole period, and $56 \%$ changed between different groups of studies, e.g., between STEM and HEALTH. The considered trajectories of the students showed that the leaking-pipeline metaphor is misleading because it suggests a linear and one-way movement, while there were students moving in as well as out of STEM trajectories. The students' reflections concerning their choice showed identity issues at all three levels of what Coté and Levine label the ego identity, the personal identity and the social identity. Furthermore, while particular incidents in the students' lives and in the outreach programme they were a part of sparked interests and reflections, these incidents should be considered as elements in a continuous reflection of students concerning who they are and where they would like to go rather than critical moments.

Keywords: Science choice, higher education, identity, recruitment, leaking pipeline, critical moments, longitudinal method

\section{Introduction}

It has been a dominant view that students lose interest in STEM as they proceed through the educational institutions and therefore opt away from STEM-related trajectories (Tytler, 2014). The 'leaking STEM pipeline' (Engineering Infrastructure Diagramming and Modeling, 1986) is frequently used for this 
observation. The metaphor suggests a well-defined flow of students from secondary school through higher education and into the STEM labour market (the pipeline), and that during this flow some students leak out of the pipeline and are lost for the STEM community (Metcalf, 2010). This has led to policy initiatives focusing on capturing young, potential STEM students and holding on to them before they drip out of the pipeline.

The metaphor is widely used, but also criticised. One critique is its focus on recruiting scientists for the STEM labour market, but ignoring broader scientific literacy aspects (Archer, DeWitt, \& Osborne, 2015). Another is that it in many ways is insensitive to variations and thus distorts the understanding of the problem. This not only concerns 'its emphasis on a neatly linear progression through a fixed set of benchmarks', but also that 'it diminishes variation in the motivation for pursuing STEM courses and the range of experiences they may offer' (Cannady, Greenwald, \& Harris, 2014, p. 448). The metaphor homogenises people and stages (Vitores \& Gil-Juárez, 2016), and fails to capture the particular cultural and contextual elements of study experiences of students from underrepresented groups (Espinosa, 2011; Mendick, Berge, \& Danielsson, 2017; Ong, 2005). Furthermore, the inclination to homogenise leads to an insufficient awareness of the point that both the identity variables and what counts as STEM can be constructed in various ways when analysing quantitative data (Metcalf, 2014).

Hence, the metaphor posits a linearity that is not accurate (Cannady et al., 2014) and it appears unable 'to account for varied career paths, exit, and re-entry' ("The Ada Lovelace project," ; Metcalf, 2010, p. 9). The pipeline metaphor thus implies that students leaving the pipeline are lost forever. However, students' educational trajectories should rather be seen as multidirectional flows where students change between STEM trajectories and non-STEM trajectories 'because there are indeed some students who are not initially interested, but are later attracted into STEM disciplines' (Sadler, Sonnert, Hazari, \& Tai, 2012, p. 412). Therefore, Metcalf (2014) calls for attention to the experiences of the students, rather than just to the numbers. Similarly, Cannady et al. (2014) state that 'the recognition of variation invites interrogation of the paths individuals take $[\ldots]$ it invites inquiry into the journey rather than simply headcounts at the mile markers' (Cannady et al., 2014, p. 455).

As it is, there is a substantial amount of research exploring students' perception of and interest in STEM subjects and their subsequent choice of a STEM-related study path. Increasingly, identity has been in focus of this research (Bøe, Henriksen, Lyons, \& Schreiner, 2011; Tytler, 2014). 'Identity' as a theoretical construct is approached from different traditions and with various focuses ranging from 
looking solely on intra-personal factors and sense of self and sameness to emphasising identity as rooted in external, social and cultural factors (Ryder, Ulriksen, \& Bøe, 2015; Shanahan, 2009).

A substantial amount of studies have found that STEM disciplines and studies are gendered (male), racialized (white) and classed (upper and middle) which in effect deter particular groups of students who do not see science as a place for them (Archer et al., 2015; Archer et al., 2012; Carlone, Haun-Frank, \& Webb, 2011; Johnson, Brown, Carlone, \& Cuevas, 2011). These studies have a particular focus on how discourses and tacit assumptions privilege certain practices and groups, and that the intersection of various elements is of importance (e.g., Ong, 2005). These processes occur in the relation between the individual and the socio-cultural environment as well as within particular social structures (Shanahan, 2009). Consequently, individual, social and psychological perspectives are all essential for a comprehensive understanding of the identity work related to students' educational choices. In 2002, Côté and Levine proposed an identity theory that accounted for these social-psychological perspectives. This theory describes three separate levels of identity that are interrelated and continuously influencing each other:

- The ego identity: the student's subjective sense of continuity of being the same person across time and across different settings.

- $\quad$ The personal identity: the student's concrete self-presentations and perceived responses rooted in interactions that are displayed as individuality.

- The social identity: the student's engagement with and perception of socioculturally available and accepted positions and roles (Côté \& Levine, 2002).

In this paper, our interest is in the recruitment of students for STEM higher-education studies rather than on science literacy (Mendick et al., 2017) or science as a 'springboard' (Archer et al., 2015). Our main concern is the question of linearity of students' educational trajectories: Is there a one-way traffic out of the pipeline or does it allow for re-entry? Our approach focuses on the students' reflections based on their experiences and through this addresses the issue of identity. Furthermore, we seek to explore the variety of plans and possible trajectories students may have over time and hence the paths and variations that the pipeline metaphor is insensitive to (cf. Mendick et al. (2017) and Cannady et al. (2014)).

To capture these multidirectional flows, we have conducted a longitudinal study focusing on the transition from upper-secondary school to tertiary education. The study addresses two research questions: 
- How stable are STEM-oriented upper-secondary school students' educational trajectories (in or out of the pipeline) over time?

- What reasons for changing their educational trajectories can be found in the students' accounts of their educational reflections?

For answering the first research question, we conducted a longitudinal quantitative analysis with three successive points probing students' educational reflections allowing us to look at multidirectional flows in and out of a STEM trajectory. For answering the second question, we examined students' accounts of their reflections concerning their educational choices and trajectories in the transition process from uppersecondary school to tertiary education and how these accounts were related to issues of the students' identity constructions.

\section{Critical moments in students' educational choice processes}

Educational systems present students with a number of transition points where they have to decide what to do next, e.g., which levels to take or which higher-education study programme to enter. Within the pipeline metaphor these transition points are perceived as junctions and potential leaks where students decide whether to follow a path leading to a STEM degree or not, with the choice of tertiary education as a particularly 'leaky’ point (Metcalf, 2010). These institutionally predefined decision points may be critical moments in the choice processes of the students. Other moments or incidents of particular significance to which path a particular student will follow may be coincidental and specific to the individual, such as an inspiring encounter with a person or an experience when visiting a museum. Furthermore, cultural assumptions and expectations concerning what is considered legitimate at a particular point in time in a particular social context, for instance, the number of gap years, affect how the students deal with critical moments (Hutters, 2004). Thus, the transition and choice processes contain more than arriving at a junction and making a decision, as could appear from the perspective of the pipeline metaphor. It entails integrating various elements into a process of identity formation and maintenance:

Numerous studies show how transitions combine turning points, milestones or life events with subtle, complex processes of 'becoming somebody' personally, educationally and occupationally' (Ecclestone, Biesta, \& Hughes, 2010, p. 7). 
As the quote suggests, various terms are used for these moments and the way they are conceived and described varies as well. Mandelbaum describes turnings as something that 'is accomplished when the person takes on a new set of roles, enters into fresh relations with a new set of people, and acquires a new self-conception' (Mandelbaum, 1973, p. 181). This addresses identity work at all three identity levels combining changes of the social identity (a new set of roles becomes available), personal identity (new relations and interactions become possible) as well as the ego identity (new self-conception appears). According to Mandelbaum, turnings occur either gradually over time or at specific turning points. These turnings could be either ascribed or self-chosen. However, the importance of the turning depends on the individual viewer (Mandelbaum, 1973).

Within a tradition of biographical research, Thomson et al. (2002) suggested the concept, critical moment, building on a critical discussion of Giddens' concept of fateful moments (Giddens, 1991). They perceive critical moments as a descriptive concept: 'an event described in an interview that either the researcher or the interviewee sees as having important consequences for their lives and identities' (Thomson et al., 2002, p. 339). Their definition implies that the researchers' analysis of interviews may allow the identification of a moment that the interviewee does not (yet) seem to acknowledge, but that is critical. The majority of their interviewees pointed out critical moments, although often retrospectively, and Thomson et al. noted that 'young people were sometimes living through experiences that they may subsequently come to understand as critical moments' (Thomson et al., 2002, p. 339). Hindsight and a longer perspective 'enabled the young people themselves to reassess and reconsider what were and were not critical moments, as they reflected on their experiences' (Holland \& Thomson, 2009, p. 455).

However, as shown by Holmegaard, Madsen, and Ulriksen (2014a) students are continuously engaged in reconstructing their narratives, and critical moments that are identified retrospectively may rather be perceived as critical to the present situation of the interviewee than to the situation to which the narrative refers.

We use critical moments as a productive lens for understanding students' reflections concerning their educational trajectories and the identity work included in these reflections. It broadens the perspective from system-based and institutional decision points to factors related to students' experiences and backgrounds and to the students' efforts to integrate decisions that are required by institutions or systems with negotiations and interpretations of their experiences as part of an identity construction. It further allows us to explore the variations in the experiences of individual students, and how the students deal 
with what they encounter during their transition period. These variations relate to all three levels of Coté and Levine's identity theory.

\section{Methods}

The present analysis builds on an outreach project at a Danish research-intensive university. The purpose of the project was to present university studies in general and STEM studies in particular as an option for students who, due to their social, ethnic or family-related backgrounds, could be less inclined to consider entering a university study than would their peers. The project involved ten upper-secondary schools selected based on the socio-economic profile of the school and their distance to a university. Hence, the participating students would predominantly come from a family background without a history of attending university. The students were recruited by their teachers based on their social background, on their STEM interests and abilities and on a written application presenting their motivation for participating. The Danish educational system requires students to make their first significant choice at the end of lower-secondary school, where they decide whether to pursue vocational education and training or upper-secondary school. Those who pursue upper-secondary school have to choose one of four types of upper-secondary schools. After having entered, they further choose between specialised study packages and elective subjects. Some of these packages and subjects give immediate access to STEM highereducation programmes, but it is possible after having completed upper-secondary school to add required STEM levels, if students wish to enter a STEM programme anyway. The choice of tertiary education is the next decision point, and a decision to change tertiary education will be considered a drop-out and reentry.

All students in this study took advanced mathematics in general upper-secondary school and therefore met the formal requirements for entering tertiary STEM educations. Hence, it was a purposeful sampling where the selected participants had parents with shorter educational background than the parents of their classmates, just as the selected students were particularly inclined to pursue STEM.

The aim of the outreach project was to qualify the educational choice processes of these students. The project ran in three rounds from 2010 to 2014 involving a total of 240 participating students ( 80 students in each round). Each round lasted the final 18 months of the students' three-year-long upper-secondary schooling. During this period, the students visited the university five times. Each time the students met in groups with two assigned mentors who introduced them to studying at university. The mentors were older 
university students from different STEM programmes. The thoughts and plans of all participants concerning their educational trajectories were probed at three reflection-points: right before and after they participated in the project and once one and a half year after having completed the project and uppersecondary school.

A sample of sixteen focus students from the first round was selected based on their applications for the project aiming to capture as diverse a range of educational reflections as possible. One focus student did not respond to requests from the researchers, but the remaining 15 focus students' educational reflections and trajectories were longitudinally investigated using mixed methods.

Figure 1 shows the time line and the different elements in the mixed methods design of the study. The elements are described in the following.

[Figure 1 around here]

\section{Educational reflection points: All project participants}

Before entering the outreach project (18 months before completing upper-secondary school) and just after the project ended (at the time of completing upper-secondary school) all participants were asked to answer the open question: Which thoughts do you have about what you would like to study, and what are your reflections concerning future education and work? The question was part of a larger web-based survey evaluating the outreach project. Further, project participants were contacted one and a half year after they completed upper-secondary school and were asked about their educational reflections related to their intended or actual educational trajectory at that particular point in time (see the left-hand side of Figure 1). 209 students ( $87 \%$ of the 240 participants) reported educational reflections at all three points.

\section{Educational reflection interviews (and Facebook messages): Focus students}

Each of the 15 focus students were interviewed eight times during their participation in the outreach project and again one and two years after they completed upper-secondary school. Additionally, they were asked three times to write down their current educational reflections in a Facebook message to the researchers (see right-hand side of Figure 1). 
The interviews were individual, qualitative, semi-structured and were conducted at the students' schools or by phone while students were at home. Each interview followed the thread and theme from the previous interview: the students' educational reflections and attitudes towards tertiary education in general and STEM educations in particular. All the qualitative interviews were recorded and transcribed verbatim.

\section{Motivation for pursuing specific educational trajectories: Focus students}

At five of the eight interviews during upper-secondary school and at the interview one year after completing upper-secondary school, the focus students filled out a survey in dialogue with the interviewer (first author of this article). Additionally, the students answered the survey in relation to the Facebook message three years after completing upper-secondary school. Each of the seven times that surveys were completed is marked with a star in Figure 1.

The survey was inspired by the Expectancy-Value model of Motivated Behavioural Choices developed by Eccles and colleagues (Wigfield \& Eccles, 2000). The model presents choice as a response to motivational beliefs rooted in expectations of success and perceived value following the choice (Bøe et al., 2011).

The survey contained 17 items using a seven-point Likert-scale. Two of the items targeted the students' motivation for pursuing specific educational trajectories: 'It is highly probable that I will end up in this educational trajectory' and 'I am highly motivated for pursuing this educational trajectory'. These two items formed the basis for the analysis of the focus students' individual educational trajectories in the present study. The use of the word 'motivation' linked to the model by Eccles and colleagues. In the interviews with students, 'motivation' was used in a common way as in an everyday conversation, and it served as an indicator of how strongly they felt about the educational trajectory in that particular situation. Neither in the interviews, nor in the analysis are we referring to a particular theoretical concept of motivation.

The Likert scale was used as a way to have the students quantify how inclined or convinced they were about their intention of pursuing a particular educational trajectory and, thereby, also how they ranked different possible trajectories compared to each other. Note, that at the first survey-fillings, the students expressed their motivation for intended trajectories. At the later survey-fillings, they could relate to actual 
educational trajectories as well as to intended, future trajectories. Throughout this paper, we thus refer to 'trajectories' as meaning both intended and actualised.

At each of the seven measurement points, the interviewees said which study programmes they were considering at that particular time and for each of the programmes they answered the two questions mentioned above. In the interviews, this allowed students to unfold experiences and reflections beyond those present in the survey, e.g., concerning their social environments. During the interview, the interviewer also referred to the study programmes and career aspirations the interviewee at previous interviews had mentioned as possible future trajectories. However, the students decided which and how many study programmes they found relevant to include, when they filled out the survey at each particular measurement point. For some students, it was just one or two study programmes at each point, while others filled out for five or more.

\section{Analysis}

Quantitative and qualitative data were analysed as described in the following subsections.

\section{The flows in participants' educational trajectories}

The educational reflections of the 209 project participants were originally categorised according to six groups based on the four faculties at the University of X-city: 'STEM' (tertiary-level STEM educations), 'HEALTH' (tertiary-level health educations), 'ARTS' (tertiary-level arts educations), 'BS' (tertiary-level business and/or social studies), 'Other' (non-university educations e.g. 'police officer') and 'Unsure' (no specific educational idea, e.g. 'a tertiary education'). However, because all the project participants had particular interests in STEM, most of their educational reflections concerned STEM and HEALTH programmes. Therefore, we merged reflections concerning ARTS and BS with the 'other' group ending up with four separate groups coloured this way throughout the paper: STEM - blue, HEALTH - red, Other - green and Unsure - orange.

At the three reflection-points, some of the students considered educational trajectories related to more than one group. When this was the case, their contribution to each of the groups was weighted. For instance, a student who wished to 'become an engineer or mathematician' contributed $100 \%$ to the STEM group, whereas a student wishing to 'become a medical doctor, a nurse or a physicist' contributed $33,3 \%$ to the STEM group and $66,7 \%$ to the HEALTH group, at that specific reflection-point. 
Changes over time in students' educational reflections were quantified as:

No change: $\quad$ Students stick to the same educational trajectory during all three reflection-points.

Within-group changes:

Between-groups changes:
Students considering different educational trajectories within one group of studies (e.g., within STEM) during all three reflection-points. Students considering educational trajectories during the three reflectionpoints that changed between two or more groups of studies (e.g. from STEM to Other).

We used Sankey diagrams to visualise the students' between-group trajectories across the three reflection-points. Sankey diagrams are particularly suitable to illustrate flows and have previously been proved appropriate to visualise educational trajectories (Sadler et al., 2012).

Additionally, we quantified the share of students staying in (no change or within-group changes), opting in (between-groups changes), opting out (between-groups changes) and staying out (no change or withingroup changes) of the STEM-pipeline during the three reflection-points.

\section{Focus students' educational trajectories and reflections}

The educational reflections of each of the 15 focus students were visualised as separate, individual educational trajectories. At each of the seven measurement points, we calculated (marked with stars in Figure 1) the mean value of the focus students' answers (on the seven-point Likert-scale) to the two questions concerning their motivation for pursuing their self-chosen intended or actual educational trajectories, and we plotted them as a function of time.

For the present analysis, we selected five case students based on maximum variation (Flyvbjerg, 2011) with one case student having no change, two having within-group changes and two having betweengroups changes in their educational trajectories.

In the interview transcripts, we extracted the sections where the students explicitly or implicitly referred to their reflections concerning choice of study and intended or actual educational trajectories. The extracts were analysed based on the theoretical framework of the study focusing on the five case students' reasons for changing their educational trajectories, and on the incidents and experiences that occurred in the student interviews that were linked to the students' choices and trajectories, irrespective of whether the 
students explicitly made this link or not. Finally, the analysis focused on the students' identity work. The analysis of each case student presented in the result section was member-checked.

\section{Results}

Results are presented in two subsections corresponding to the two research questions. The first section presents the dynamics in the participants' considerations regarding educational trajectories over time, and the second presents the case students' individual intended and actual educational trajectories and their accounts for within-groups and between-groups changes.

\section{Students' educational trajectories}

Of the participating students, $22 \%$ expressed the same intended and/or actual educational trajectory during all three years. Particularly students considering medicine (two fifths of the 'no change' students) maintained the same intention over the period. Another $22 \%$ of the participating students changed between educational trajectories within one group of studies during the three years (two thirds of the 'within-group changers' was within STEM and one third within HEALTH). More than half the participating students (56\%) changed between different groups of studies during the one and a half year before and after they completed upper-secondary school.

Figure 2 visualises the students' educational trajectories. The horizontal dimension shows time with the three reflection-points indicated at the top. These three points correspond to the three arrows in the left side of figure 1 indicating educational reflection points. The vertical dimension present the distribution of the 209 students in four different groups according to which educational trajectory they expressed at each of the three reflection points. The percentage indicated in the dashed arrows is the share of the students within the group at that point. Hence, at the first reflection point, $43 \%$ of the students indicated that they intended to pursue an educational trajectory within STEM, while, at the third reflection point, $54 \%$ of the students had either entered or intended to enter a STEM trajectory.

The coloured bands illustrate the flows between the four groups of study programmes, The widths of the individual coloured bands are proportional with the share of participating students in each trajectory. The proportion of students who "stay in the STEM pipeline" are thus the wide blue horizontal band at the very top. This band includes both students with 'no change', who stick to the same specific educational trajectory over time (e.g. Physics at all three measurement points) and students with 'within-group 
changes' who change between specific but related trajectories within STEM, e.g. Physics at first measurement point and Chemistry at second measurement point.

[Figure 2 around here]

The range of different patterns represented in the flow diagram emphasises that there is not one typical educational trajectory common for the participating student cohort. Of the 64 potential trajectories between the four groups, 45 trajectories are represented by this study's participants. However, the vast majority of the students who at the first reflection point were unsure about which trajectory to enter ended up pursuing a STEM education. Since the participants in the project were selected based on their interest in STEM, this is less surprising and cannot be generalised to all groups of students.

It is striking that although very few students (only $3 \%$ ) were uncertain about their educational trajectory by the time they completed upper-secondary school, more than every fourth student (28\%) eventually changed between groups of study programmes during the first year and a half after completing uppersecondary school. We shall later discuss how this illustrates the elusiveness of intended educational trajectories.

[Table 1 around here]

Table 1 shows the total amount of students who at all the three reflection points said they intended to pursue a STEM trajectory, the amount of students who at none of the three points said they would enter a STEM trajectory, the amount of students who first indicated not to pursue STEM, but at a later reflection point opted into a STEM trajectory, and finally the amount of students who first indicated they would follow a STEM trajectory and in following reflection points decided not to. More than two in every three participating students (71\%), at one point during our study, was on a STEM trajectory. If one should use the metaphor of the STEM pipeline, we found that more participating students opted into the STEMpipeline than students opting out. 


\section{Students' educational reflections}

An overview of all 15 focus students' intended and actual educational trajectories are represented in figure 3. Each vertical arrow indicates a student's trajectory from 18 months before completing uppersecondary (top) to three years after completing upper-secondary school (bottom). The colour shows within which field of study the student at various points in time intended to pursue higher education. The students are divided in three groups according to whether they changed between groups of study (righthand group), changed programme within a group of study programmes (centre group) or considered the same study programme during the whole period (left-hand group). The name of the programme they eventually decided to enter (the actual trajectory) when our study ended is written across the arrow at the point in time, when they first mentioned it as the study path they were motivated for pursuing. Most of the changes concern intended study paths (shaded arrows in figure 3), but some students actually entered one study programme only to leave it again and enter another. The arrows at the top, thus, illustrate intended study trajectories (shaded) while the bottom arrows (full-coloured) show actual paths. Hence, the arrow of students who left a study programme they had entered will change from full-coloured to either a shaded arrow (e.g. Benji ${ }^{2}$ ) or to a new full-coloured arrow (e.g. Robert), depending on whether they changed directly from one study programme to another (Robert) or whether they had a break in between (Benji).

The selected five case students' whose individual educational trajectories and concomitant reflections will be presented in the following are indicated in Figure 3 with grey background.

[Figure 3 around here]

Caroline - no change

Figure 4 shows an overview of Caroline's intended and actual educational trajectory.

[Figure 4 around here]

\footnotetext{
${ }^{2}$ All names of students used in the article are pseudonyms
} 
Figure 4 shows that Caroline during upper-secondary school gradually became increasingly determined to pursue a medicine degree. At the first measurement point (indicated by the arrow labelled 'Third interview'), Caroline expressed a high motivation for studying medicine (the red dot between the sixth and seventh upper vertical lines). The solid, horizontal lines in the figure refer to the seven-point Likertscale indicating the level of motivation for a particular intended or actual study trajectory. It can be seen by following the dashed line to the second measurement point ('Fourth interview') that Caroline's inclination to study medicine increases even further and through the following five measurement points it remains at the top seventh line.

The figure further shows that at the first measurement point, Caroline mentioned Physics (blue dot), Nurse (light pink dot) and Physiotherapy (hot pink dot) as other possible paths of study. She considered them as alternatives to medicine, but without having any strong motivation for pursuing them, hence scoring them lower on the Likert scale which in the figure is expressed by the dots being at lower horizontal lines. By following the dashed lines through the subsequent measurement points, it is shown that Caroline became even less motivated to pursue these trajectories leaving them at the bottom line at the fourth point. In the figure, only the hot pink dot is visible, but the three dashed lines leading to the dot indicate that all three possible trajectories have received the same ranking by Caroline. At the fifth measurement point just before graduating from upper-secondary school (eighth interview), only Physics was left as an alternative to medicine and with a slightly higher motivation than at the previous measurement point (sixth interview). At the final two measurement points, one year (ninth interview) and three years after graduation (third Facebook message) respectively, Caroline was only motivated for pursuing medicine and only one dot is shown in the figure.

In the qualitative interviews, Caroline presented her reflections concerning the different possible trajectories. During upper-secondary school, Caroline became interested in both physics and biology. It was, however, important for her to help others and she had always dreamt of working at a hospital. She had herself been hospitalised a few times and had found the doctors' work fascinating. She thought it would be interesting to work with the human body, but she was not sure she would achieve the grade- 
point average (GPA) required to study medicine ${ }^{3}$. Because of this, and because she was a bit worried about whether she could handle the pace at university, she, for a time, considered becoming a physiotherapist or a nurse. Both programmes are shorter than medicine and offered at university colleges rather than universities. However, during the outreach project, she became more confident that entering university would be the right path for her. She therefore rejected the shorter nurse and physiotherapy study trajectories. At the end of upper-secondary school, it was thus clear to her that, if she could not enter medicine, she would certainly 'do something else at university and it might be becoming a physicist' (eighth interview), even though she preferred helping people more directly than what would be possible if she studied physics.

For Caroline, the main drawbacks in medicine were that she had to study for so long, that it would probably be tough, and that it might affect her leisure time, family life and social life. However, if she achieved the required GPA, she was determined to become a medical doctor, since it was the only thing completely compatible with her self-image. Caroline was willing to move to anywhere in the country and start whenever possible, if she could be admitted to medical school.

Six months after Caroline completed upper-secondary school (about the time of the first Facebookmessage), she began studying medicine and she has not reconsidered her educational trajectory even once.

\section{Robert - within-group changes}

Robert's educational trajectory initially resembled Caroline's with gradual clarification throughout uppersecondary school, leaving physics (dark blue line in Figure 5) as the only thing he is motivated for pursuing and engineering as an alternative, but where he expressed a much lower motivation for pursuing that trajectory (lighter-blue line). However, one year after finishing upper-secondary school, Robert's priority between the two had changed and he now wished to become an engineer, rather than studying physics (hence, the dark blue physic-line drops to a very low level at the ninth interview and the lighterblue rose to the top horizontal line).

${ }^{3}$ In Denmark students are admitted to tertiary education based on their upper-secondary school GPA. 
[Figure 5 around here]

At the beginning of the outreach project, Robert was certain he would take some kind of university education; he just was not sure which trajectory to pursue. He considered whether engineering or a science education (probably physics) would suit him best. However, he thought that 'physics is a dead subject where everything has already been proven' (first interview), but hearing a 'real PhD student' presenting his $\mathrm{PhD}$ project during the outreach project convinced Robert that there were still things to discover in science.

Robert briefly considered chemistry and nanotechnology, but he was mostly interested in physics: 'It is because I have realized that I am actually damn good at it' (fourth interview). Robert's upper-secondary school did not offer A-level physics which is mandatory for entering tertiary physics in Denmark. Therefore, Robert reconsidered studying engineering. 'Mostly, it is just a backup, but a backup I am fairly sure that I will never use' (fifth interview). Instead, Robert moved to another city to take a supplementary physics course during the summer break after finishing upper-secondary school, and right after this, he began studying physics at university. Half a year later, Robert wrote in a Facebook message:

The studies are 90\% algebra, it was boring, honestly felt like I didn't learn anything except solving equations. [...] During my studies I found out that I would much rather do programming Robert quit the physics study and started a new educational trajectory - an engineering study in information and communication technology. 'When I look back, I feel that it was always here I was supposed to end up' (second Facebook-message). Two and a half years into the study, he was still happy about this choice: 'Changing to engineer is one of the best decisions I have made, and I am super happy about it' (third Facebook-message).

\section{Mathew - within-group changes}

Mathew, like Robert, changed between two related trajectories within STEM; mathematics (dark blue line in Figure 6) and computer science (light blue line in Figure 6). The figure shows that through uppersecondary school (the first four measurement points indicated with coloured dots) he did not feel a particular strong inclination to pursue either of the two (both the dart-blue and the light-blue dots and 
dashed lines are between the fourth and fifth horizontal lines). By the end of upper-secondary school and of the outreach projects, his motivation for pursuing mathematics rose, while he expressed less motivation for computer science (fifth measurement point, eighth interview). However, after one gap year, this had reversed and computer science was now at the top horizontal line.

[Figure 6 around here]

When reflecting on his educational trajectory Mathew initially searched for his one great interest, 'something I can really be dedicated to' (first interview). From his dad, who was working as a system developer, he knew that 'if you are dedicated to something then you don't mind spending your spare time working with it as well' (first interview). Mathew, however, could not come up with anything he was really dedicated to besides the computer game World of Warcraft. He believed he needed to be very dedicated to a potential educational trajectory, if he should not 'lose my motivation for the study and not be able to pull myself together to read what is required' (first interview).

Mathew did not experience himself as dedicated to STEM, but still, in school, it was the STEM subjects he was mostly interested in. Mathew therefore first thought about studying mathematic; he had always been interested in mathematics, but he was a little worried that it would be 'too much' (first interview). Mathew began considering studying computer science - that one would often work with actual problems appealed to him - but he also worried that he might become too enveloped in the studies and become way too nerdy. He also worried that programming might actually be too difficult for him (fourth interview). At the end of his second year in upper-secondary school, Mathew experienced serious school fatigue, which made him consider pursuing a psychology or social science trajectory. At this point he was 'severely at a loss' (fifth interview). He said he had 'always' been interested in science and had believed he would pursue it, but suddenly found himself considering completely different educational trajectories. The outreach project made Mathew realise that tertiary STEM students were probably not as nerdy as he had imagined. After this, Mathew could 'clearly feel that science has the most pull' (fifth interview) and he returned to considering either mathematics or computer science.

Mathew also realised that programming was not as difficult as he had initially assumed, but he still had his doubts about whether he would end up studying computer science. About the time he completed upper-secondary school, Mathew proclaimed that he had decided to pursue a mathematics trajectory: ' $I$ 
am afraid of becoming too attached to the computer. I do not want to be the kind of person who almost needs a sling to carry his computer' (eighth interview).

During his gap year, Mathew began reconsidering studying computer science after talking with his father.

I have always used the computer a lot, and it seems more and more natural to me that it is where I should continue. Also, I have become more sensible about doing things away from the computer, so I don't see a problem in having it as my primary tool in my everyday life as well (first Facebookmessage)

Mathew started studying computer science after a gap year. Two years into the study (third Facebookmessage), he was still very pleased with his educational trajectory.

\section{Benji - between-groups changes}

As is evident in Figure 7, Benji's intended educational trajectory during upper-secondary school was essentially a choice within STEM between physics (light blue) and engineering (dark blue). However, three years after completing upper-secondary school Benji changed his trajectory to become a teacher (categorised as 'other studies' indicated by a lime-green dot at the third Facebook-message) even though he abandoned this specific educational trajectory after the first measurement point (lime-green dot at the third interview - but not at any of the following).

[Figure 7 around here]

Benji's intention was to major in social science in upper-secondary school, but because of large class sizes he was randomly selected to major in science instead. He liked his new classmates and teachers and figured out that science - and especially physics - was not as hard as he had imagined, and he actually found it quite interesting (first interview). He therefore wished to pursue some kind of tertiary science education, but he was concerned if it would be too 'dry and individualised for him (second interview). When reflecting about education, the social aspect was very important to Benji. It meant a lot that he did not have to sit and wrestle with everything by himself. 
At the third interview, Benji considered a variety of paths, including becoming a teacher, but during the outreach project, he was introduced to different science disciplines, and he abandoned the teacher trajectory after the third interview.

Meeting a physics student convinced Benji that he should study physics (fourth interview) and several talks with the physics student through the project made him more certain: 'Every time we come to the university, my wish to go study there becomes even higher, because I like that nice study life you have' (fifth interview). However, Benji still appreciated the practical aspects of the engineering study and therefore he did not leave this option behind altogether.

After a gap year, Benji began studying the engineering programme 'Physics and technology'. He chose this trajectory because'70\% of my friends have moved to [the city offering this education] this year, and $20 \%$ will go there this summer, whereas only $10 \%$ are going to [the city where I previously wanted to study]' (first Facebook-message).

Benji quit studying engineering within half a year. 'During these past five months I have been able to feel that the life as an engineer is not exactly perfect for me' (second Facebook-message). He then considered becoming an occupational therapist or a teacher, because 'I have always loved dealing with people' (second Facebook-message). In the following Facebook message, he described that leaving the engineering programme 'was not an easy decision' and he experienced it as 'a big defeat for me, but I finally admitted that I had to do something in life that I would be happy about and motivated for in the long run' (third Facebook-message).

Benji's idea about becoming a teacher was to teach mathematics, sports and science to lowersecondary school students. 'So in that way I still manage to keep my interest in science, and at the same time I have the chance to interact socially with lots of young people' (third Facebook-message). Hence, although Benji opted away from a designated STEM trajectory, he still sought to stay within the field of STEM.

\section{Christopher - between-groups changes}

Christopher's intended and actual educational trajectory is shown in Figure 8. During upper-secondary school, he considered a wide array of educational trajectories shown by the six different coloured dots and dashed lines over the four first measurement points. After finishing upper-secondary school, he moved back and forth between two of them - one within STEM ('chemistry and technology' - blue line 
in Figure 8) and one within HEALTH (physiotherapy - red line in Figure 8) which he had mentioned at the two first measurement points (third and fourth interviews), but then abandoned.

[Figure 8 around here]

Christopher wished to pursue an educational trajectory that would be more practical than theoretical preferable within chemistry. He liked to 'get his hands dirty' (first interview) and considered studying 'Chemistry and technology'. Initially, Christopher's alternatives were 'agriculture, food and environment', 'a bit because my dad is a farmer' (second interview), or physiotherapy; 'I have been through rehabilitation myself, I think it would be great if I could try that some time' (third interview). During the outreach project, Christopher was introduced to several studies that took his attention away from 'chemistry and technology'. First, he met a biotechnology student who 'was spirited, funny and energetic' (fourth interview) and made him keen to study that. Subsequently, he heard about the study programme 'chemistry and biotechnology' which appealed to him because it combined his chemistry interest with biotechnology (fifth interview). A student counsellor then told him about the "chemical engineering' study programme in another city which appealed to him because it was practically oriented (sixth interview).

When completing upper-secondary school, Christopher made his first between-group change from the biology/chemistry-oriented STEM educational trajectories (the different blue lines in Figure 8) to a HEALTH educational trajectory: Physiotherapy (red line), which he had previously abandoned, was now his first priority, partly because it was practical, but also because he would be

able to help others with, well, I have been through the system a couple of times myself, because I have been injured and seen what they do, so that actually interests me a bit more (eighth interview).

Six months after completing upper-secondary school (and one knee operation later), Christopher was both interested in studying physiotherapy and 'chemistry and technology', but, after having finished a gap year, he entered 'chemistry and technology' because he thought that he had 'invested too much in science' during upper-secondary school to just forget all about it (ninth interview). 
However, he soon realised that it was not the right educational trajectory for him: 'I think it simply became too theoretical' (third Facebook-message), and six months later he started studying physiotherapy.

After one year of studying physiotherapy, Christopher took leave as he 'had had a period of time where he tired somewhat of it' (third Facebook-message), but still planned on returning after six months' break. 'I particularly had trouble with physiology, so my leave of absence will be spent on catching up and getting better prepared to start again' (third Facebook message).

\section{Patterns and moments in the students' trajectories}

\section{The stability of students' educational trajectories over time}

The quantitative analysis of the intended and actual trajectories of the entire cohort of participating students (Figure 2 and Table 1) and the more detailed analysis of the trajectories of the case students (figures 4-8) show that the students' ideas about their educational trajectories and their actual movements in general are not stable over time. The time in and after upper secondary school is thus a period of intense identity work and extensive considerations and reconsiderations regarding future career and educational trajectory. The majority of the students changed their trajectories over time, although some educational reflections appeared more stable than others, particularly medicine. Moreover, more than half of the students' educational trajectories changed between studies at different faculties. This extent of between-groups changes was surprising and noteworthy. It highlights the dynamics in students' educational choice processes, and it questions the leaking STEM pipeline metaphor.

Figure 2 and Table 1 show a substantial movement of students both in and out of the so-called STEM pipeline. Hence, some of the students who took high-level STEM subjects in upper-secondary school, but thought to follow non-STEM trajectories, at a later stage flow back in. This indicates that students who leave a STEM path at one point have not necessarily left STEM forever, contrary to what the pipeline metaphor misleadingly implies.

In the analysis, we have included intended trajectories as well as actual study paths. This allows us to see how the choice process is experienced by the student and thus the dynamics of considerations concerning whether to pursue a STEM trajectory or not in a way that would not be possible, if we had only looked at 'actual trajectories'. It not only reveals the continuous doubts and changes of many of the students. It 
further emphasises that the decision process does not necessarily end with matriculation, as shown by the students who leave one study programme to enter another. This is coherent with understanding choice of education as closely linked to identity formation and identity work (Holmegaard, Madsen, \& Ulriksen, 2014b; Holmegaard, Ulriksen, \& Madsen, 2015)

The qualitative data moreover suggest that students may not always perceive between-group changes as major changes in their educational trajectory. Changing from medicine (HEALTH) to molecular biology (STEM) could, for instance, be considered as biology-stable, and changing from physics (STEM) to economics (Other) as mathematics-stable. Research needs to consider that stability may be of more than one kind. This underpins the points mentioned earlier made by Metcalf (2014) about the construction of variables (such as 'STEM') and by Cannady et al. (2014) about recognising variation in individual paths.

\section{Students' accounts for changes in their educational trajectories}

The students included in this study participated in an outreach project designed to facilitate potential critical moments: Meeting tertiary STEM students, getting information about different educational trajectories, etc. We therefore expected that the qualitative analysis would reveal evidence of critical moments where the case students changed between considering different educational trajectories. We found examples that the outreach project created moments that made students consider pursuing a tertiary STEM education. The project's activities made both Benji and Christopher discover study programmes they found interesting, Matthew changed his perception of STEM students, and Benji experienced the study environment as social and attractive. However, none of the moments related to specific study programmes eventually made the students enter that particular programme (although Benji entered a physics-related engineering programme). Still, the general impressions of science and science students seem to have had an impact by showing STEM as a study environment the students could imagine themselves being part of. This suggests that critical moments, like those orchestrated by the outreach programme, can spark an interest, but it is less certain that the interest will persist. However, it also suggests that experiences changing more general perceptions and prejudices can have an impact. Other kinds of critical moments affected students' considerations. These related to personal experiences such as Caroline and Christopher having personal experiences with the health system. Matthew experiencing school fatigue and Benji's and Robert's experiences of the programmes they entered could also be perceived as critical moments making the students reconsider their trajectories and choices. For 
Caroline and Christopher, their personal experiences affected their decisions about which programme to enter; for Benji and Robert it made them opt out of their programme. This suggests that the impact of critical moments should be seen in relation to the students' reflections related to their identities, but also that some of the 'moments' refer to experiences over some time.

\section{Choice and identities}

The students' reflections concerning their study trajectories mainly referred to the ego identities (who they perceive themselves to be across time) and to their personal identities (their self-representation and interaction with others).

When Caroline wished to do something 'compatible with her self-image' and emphasised her interest in helping others, and when Christopher talked about the 'nature of the discipline' and getting 'his hands dirty' they both referred to the compatibility between the study trajectory they considered and their perception of themselves. Similarly, when Mathew wanted to 'find something he could be truly dedicated to', and Benji said that he had 'always' been interested in a particular field they presented an image of an almost inherent link between the course of study and who they are, i.e., their ego identity. Aspects related to the personal identity concerned how the study would affect their interactions with and relation to others (e.g., Matthew's worries of becoming 'the type of person' attached to a computer or Benji's valuing of the social live at university).

Reflections related to the social identity were more rare. There can be different reasons for this. One could be that because the three identity levels are interrelated, it is not always analytically possible to distinguish one level from the other. Another could be that the social identity is of no importance, since it is not present in the material, but rather we believe it concerns the social and cultural aspects of identity work and identity formation as such. As mentioned earlier, the social level of identity concerns what is perceived as socioculturally available and accepted positions and roles (Côté \& Levine, 2002). Numerous studies have shown that these are perceived and communicated in subtle and often tacit ways (see Archer et al., 2012; Carlone \& Johnson, 2007; Danielsson, 2012; Ong, 2005, p. to name a few). Consequently, what is closely related to what is acceptable and available (the social identity) may by the student be perceived as an individual or relational decision. Therefore, these aspects will not be expressed as social in their narratives. Further, the expectation of the individual to construct and decide their own biographical trajectory that is endemic in modern societies (Beck \& Beck-Gernsheim, 2002; Schreiner \& 
Sjøberg, 2007; Ziehe, 1991) makes it likely that the students' narratives will omit those aspects where the socio-cultural level limited or decided their paths (cf. Holmegaard (2015)).

An exception among the focus students in the present project was Mary (not one of the case students in this paper). She decided to enter a study programme she had not mentioned in previous interviews, but which her family and friends appreciated (Lykkegaard \& Ulriksen, 2016). Among the case students in this paper, Caroline mentioned that she would pursue university physics rather than nursing (universitycollege level), if she could not enter medicine (university level). This emphasis on the programme level rather than the field of study could be interpreted as an emphasis on the social status of a study trajectory (social identity), but we cannot conclude that decisively.

\section{Choice, critical moments and identities}

The students' trajectories and their reflections concerning what to choose were related to their identity perceptions and constructions. The students were continuously engaged in reflections about how particular choices would fit their ideas about who they were, who they wished to become and how they were perceived by others. The outreach project offered ideas and perspectives contributing to this process, as did the students' experiences in upper-secondary school, at the programmes they entered and in their lives in general (e.g., Christopher's mentioning his father being a farmer as a reason for considering agricultural studies). Therefore, the critical moments the students experienced became parts of an identity-formation process occurring over time relating to the ego-identity, the personal identity and, although less explicitly, to the social identity (Côté \& Levine, 2002). Rather than talking about critical moments as singular, salient points, they should be perceived as prolonged critical experiences over time (a similar point is made in Thomson and Holland (2015)). This could also explain why those parts of the outreach project that affected the students' fundamental perceptions of science studies and science students appeared to be more persistent than those igniting a specific interest in a particular discipline. The former can inform the process of identity formation while the latter is more at risk of (after the immediate fascination) being incompatible with the continuous process of identity formation. How the critical moments affect the students' choices depend on the extent to which they can become a part of an identity construction over time. Thus, the activities in the outreach projects that could have been critical moments and where some of them changed some of the students' perceptions and ideas are in the process of choosing and following an educational trajectory rather to be seen as components or pieces that the 
students draw on in their construction of an identity. Hence, the importance and interpretation of particular incidents or experiences can change over time, as the identity work of the students evolves. The time issue suggests why the flow of students is not in one direction only (as the pipeline metaphor erroneously implies), but have students moving in and out of the STEM trajectory. Students engage in a continuous interpretation of what they experience and in these interpretation and negotiation processes, what at one point directed the students away from a STEM trajectory could in a later context, e.g., based on different experiences, be reinterpreted in a way that would direct the student back into it.

\section{Conclusions}

Many students change intended or actual educational trajectories during and after upper-secondary school. Educational trajectories are elusive with students changing within one group of related study programmes, but also between fields of studies. We found students changing from a STEM trajectory to a non-STEM trajectory as well as vice versa. Hence, for the STEM-oriented students in our study the metaphor of a leaking STEM pipeline does not apply. In fact, more students opted into than out of a STEM trajectory. Furthermore, what in a STEM-non-STEM distinction appeared to be changes between fields of study could from the point-of-view of the student be seen as changes between similar study paths, e.g., having a mutual foundation in mathematics. This supports the critique of the rigid categorisation of what is STEM and what is not.

Although few students appeared to be unsure about their educational trajectory, when they completed upper-secondary school, many students eventually changed their intended trajectory after this point in time. The choice of an educational trajectory is an ongoing process (cf. Holmegaard, Ulriksen, \& Madsen, 2014) where students interpret and negotiate their experiences in relation to the formation of an identity at all the three identity levels. This has two implications.

Measures taken to inform (or affect) students' educational trajectories should have the complexity and dynamic character of the trajectory in mind. Critical moments can spark reflections, but will not necessarily lead to decisions. Later experiences or changing perceptions might change the role of a particular experience. The measures should be perceived as contributions to the students' reflection processes rather than as convincing incidents making the student make a final decision.

The second implication is that the restrained, linear image of a pipeline does not appropriately capture the trajectories and choice processes of the students. The metaphor of landscapes suggested by Vitores and 
Gil-Juárez (2016) seems more accurate to picture the possible trajectories of the students on various paths in an open space.

Studies of students' choice of education should be done over time, they should be attentive to the interrelation of different levels of identity formation, and they should abandon the pipeline metaphor as misleading because it claims study paths and decision making to be linear processes in a one-way street. This is not the case; students leaving the STEM trajectory need not be lost forever. They may be exploring the landscape, they may return to previous paths, and they may perceive the landscape in other categories than STEM or non-STEM.

\section{References}

The Ada Lovelace project. Retrieved from http://www.ada-lovelace.com/english/

Archer, L., DeWitt, J., \& Osborne, J. (2015). Is Science for Us? Black Students' and Parents' Views of Science and Science Careers. Science Education, 99(2), 199-237. doi:10.1002/sce.21146

Archer, L., DeWitt, J., Osborne, J., Dillon, J., Willis, B., \& Wong, B. (2012). "Balancing acts": Elementary school girls' negotiations of femininity, achievement, and science. Science Education, 96(6), 967989. doi:10.1002/sce.21031

Beck, U., \& Beck-Gernsheim, E. (2002). Individualisation. Institutionalized Individualism ad its Social and Polical Consequences. Los Angeles - New Delhi - Singapore - Washington DC: Sage Publications.

Bøe, M. V., Henriksen, E. K., Lyons, T., \& Schreiner, C. (2011). Participation in science and technology: young people's achievement-related choices in late-modern societies. Studies in Science Education, 47(1), 37-72. doi:10.1080/03057267.2011.549621

Cannady, M. A., Greenwald, E., \& Harris, K. N. (2014). Problematizing the STEM Pipeline Metaphor: Is the STEM Pipeline Metaphor Serving Our Students and the STEM Workforce? Science Education, 98(3), 443-460. doi:doi:10.1002/sce.21108

Carlone, H. B., Haun-Frank, J., \& Webb, A. (2011). Assessing equity beyond knowledge-and skills-based outcomes: A comparative ethnography of two fourth-grade reform-based science classrooms. Journal of Research in Science Teaching, 48(5), 459-485.

Carlone, H. B., \& Johnson, A. (2007). Understanding the science experiences of successful women of color: Science identity as an analytic lens. Journal of Research in Science Teaching, 44(8), 1187-1218. doi:Doi 10.1002/Tea.20237

Côté, J. E., \& Levine, C. G. (2002). Identity Formation, Agency, and Culture - A Social Psychological Synthesis: Lawrence Erlbaum Associates Inc.

Danielsson, A. T. (2012). Exploring woman university physics students 'doing gender'and 'doing physics'. Gender and Education, 24(1), 25-39.

Ecclestone, K., Biesta, G., \& Hughes, M. (2010). Transitions in the lifecourse. The role of identity, agency and structure. In K. Ecclestone, G. Biesta, \& M. Hughes (Eds.), Transitions and learning throug the lifecourse. Oxon: Routledge.

Engineering Infrastructure Diagramming and Modeling (978-0-309-03639-9). (1986). Retrieved from Washington, DC: http://www.nap.edu/catalog/587/engineering-infrastructure-diagramming-andmodeling

Espinosa, L. (2011). Pipelines and Pathways: Women of Color in Undergraduate STEM Majors and the College Experiences That Contribute to Persistence. Harvard Educational Review, 81(2), 209241. doi:10.17763/haer.81.2.92315ww157656k3u

Flyvbjerg, B. (2011). Case study. In N. K. Denzin \& Y. S. Lincoln (Eds.), The Sage Handbook of Qualitative Research (pp. 301-316). Thousand Oaks, CA.: Sage.

Giddens, A. (1991). Modernity and Self-Identity. Self and Society in the Late Modern Age. Cambridge: Polity Press. 
Holland, J., \& Thomson, R. (2009). Gaining perspective on choice and fate: revisiting critical moments. European societies, 11(3), 451-469.

Holmegaard, H. T. (2015). Performing a Choice-Narrative: A qualitative study of the patterns in STEM students' higher education choices. International Journal of Science Education, 37(9), 1454-1477. doi:10.1080/09500693.2015.1042940

Holmegaard, H. T., Madsen, L. M., \& Ulriksen, L. (2014a). A journey of negotiation and belonging: understanding students' transitions to science and engineering in higher education. Cultural Studies of Science Education, 9(3), 755-786. doi:10.1007/s11422-013-9542-3

Holmegaard, H. T., Madsen, L. M., \& Ulriksen, L. (2014b). To Choose or Not to Choose Science: Constructions of desirable identities among young people considering a STEM higher education programme. International Journal of Science Education, 36(2), 186-215. doi:10.1080/09500693.2012.749362

Holmegaard, H. T., Ulriksen, L., \& Madsen, L. M. (2015). A Narrative Approach to Understand Students' Identities and Choices. In E. K. Henriksen, J. Dillon, \& J. Ryder (Eds.), Understanding Student Participation and Choice in Science and Technology Education. London: Springer

Holmegaard, H. T., Ulriksen, L. M., \& Madsen, L. M. (2014). The Process of Choosing What to Study: A Longitudinal Study of Upper Secondary Students' Identity Work When Choosing Higher Education. Scandinavian Journal of Educational Research, 58(1), 21-40. doi:10.1080/00313831.2012.696212

Hutters, C. (2004). Mellem lyst og nødvendighed: en analyse af unges valg af videregående uddannelse. [Between Desire and Necessity: an analysis of young people's choices of higher education] Doctoral dissertation

Johnson, A., Brown, J., Carlone, H., \& Cuevas, A. K. (2011). Authoring identity amidst the treacherous terrain of science: A multiracial feminist examination of the journeys of three women of color in science. Journal of Research in Science Teaching, 48(4), 339-366.

Lykkegaard, E., \& Ulriksen, L. (2016). Choices and changes: Eccles' Expectancy-Value model and uppersecondary school students' longitudinal reflections about their choice of a STEM education. International Journal of Science Education, 38(5), 701-724.

Mandelbaum, D. G. (1973). The Study of Life History: Gandhi. In: University of Chicago Press.

Mendick, H., Berge, M., \& Danielsson, A. (2017). A Critique of the Stem Pipeline: Young People's Identities in Sweden and Science Education Policy. British Journal of Educational Studies, 65(4), 481-497. doi:10.1080/00071005.2017.1300232

Metcalf, H. E. (2010). Stuck in the Pipeline: A Critical Review of STEM Workforce Literature. InterActions: UCLA Journal of Education and Information Studies, 6(2).

Metcalf, H. E. (2014). Disrupting the pipeline: critical analyses of student pathways through postsecondary STEM Education. New Directions for Institutional Research, 2013(158), 77-93.

Ong, M. (2005). Body projects of young women of color in physics: Intersections of gender, race, and science. Social Problems, 52(4), 593-617.

Ryder, J., Ulriksen, L., \& Bøe, M. (2015). Understanding Student Participation and Choice in Science and Technology Education: The Contribution of IRIS. In E. K. Henriksen, J. Dillon, \& J. Ryder (Eds.), Understanding Student Participation and Choice in Science and Technology Education (pp. 351366): Springer Netherlands.

Sadler, P. M., Sonnert, G., Hazari, Z., \& Tai, R. (2012). Stability and volatility of STEM career interest in high school: A gender study. Science Education, 96(3), 411-427.

Schreiner, C., \& Sjøberg, S. (2007). Science education and youth's identity construction - two incompatible projects? In D. Corrigan, J. Dillon, \& R. Gunstone (Eds.), The Re-Emergence of Values in Science Education (pp. 231-247). Rotterdam/Taipei: Sense Publishers.

Shanahan, M.-C. (2009). Identity in science learning: exploring the attention given to agency and structure in studies of identity. Studies in Science Education, 45(1), 43-64. doi:10.1080/03057260802681847

Thomson, R., Bell, R., Holland, J., Henderson, S., McGrellis, S., \& Sharpe, S. (2002). Critical moments: Choice, chance and opportunity in young people's narratives of transition. Sociology-the Journal of the British Sociological Association, 36(2), 335-354. doi:Doi 10.1177/0038038502036002006

Thomson, R., \& Holland, J. (2015). Critical moments? The importance of timing in young people's narratives of transition. Handbook of children and youth studies, 1-9.

Tytler, R. (2014). Attitudes, Identity, and Aspirations Toward Science. In N. G. Lederman \& S. K. Abell (Eds.), Handbook of Research on Science Education Volume II (pp. 82-102). New York \& Oxon, UK: Taylor \& Francis. 
Vitores, A., \& Gil-Juárez, A. (2016). The trouble with 'women in computing': a critical examination of the deployment of research on the gender gap in computer science. Journal of Gender Studies, 25(6), 666-680. doi:10.1080/09589236.2015.1087309

Wigfield, A., \& Eccles, J. (2000). Expectancy-value theory of achievement motivation. Contemporary Educational Psychology, 25(1), 68-81.

Ziehe, T. (1991). Zeitvergleiche. Jugend in kulturellen Modernisierungen. . Weinheim - München: Juventa Verlag. 
Table 1: Participating students' educational trajectories in and out of the so-called STEM pipeline

\begin{tabular}{|l|c|}
\hline Participating students' trajectories & Share of participants \\
\hline Stayed in a STEM trajectory & $28 \%$ \\
Opted into* a STEM trajectory & $26 \%$ \\
\hline Stayed out of a STEM trajectory & $29 \%$ \\
Opted out of** a STEM trajectory & $17 \%$ \\
\hline
\end{tabular}

* $4 \%$ of all participants opted first out of and then into a STEM trajectory.

** $11 \%$ of all participants opted first into and then out of a STEM trajectory. 


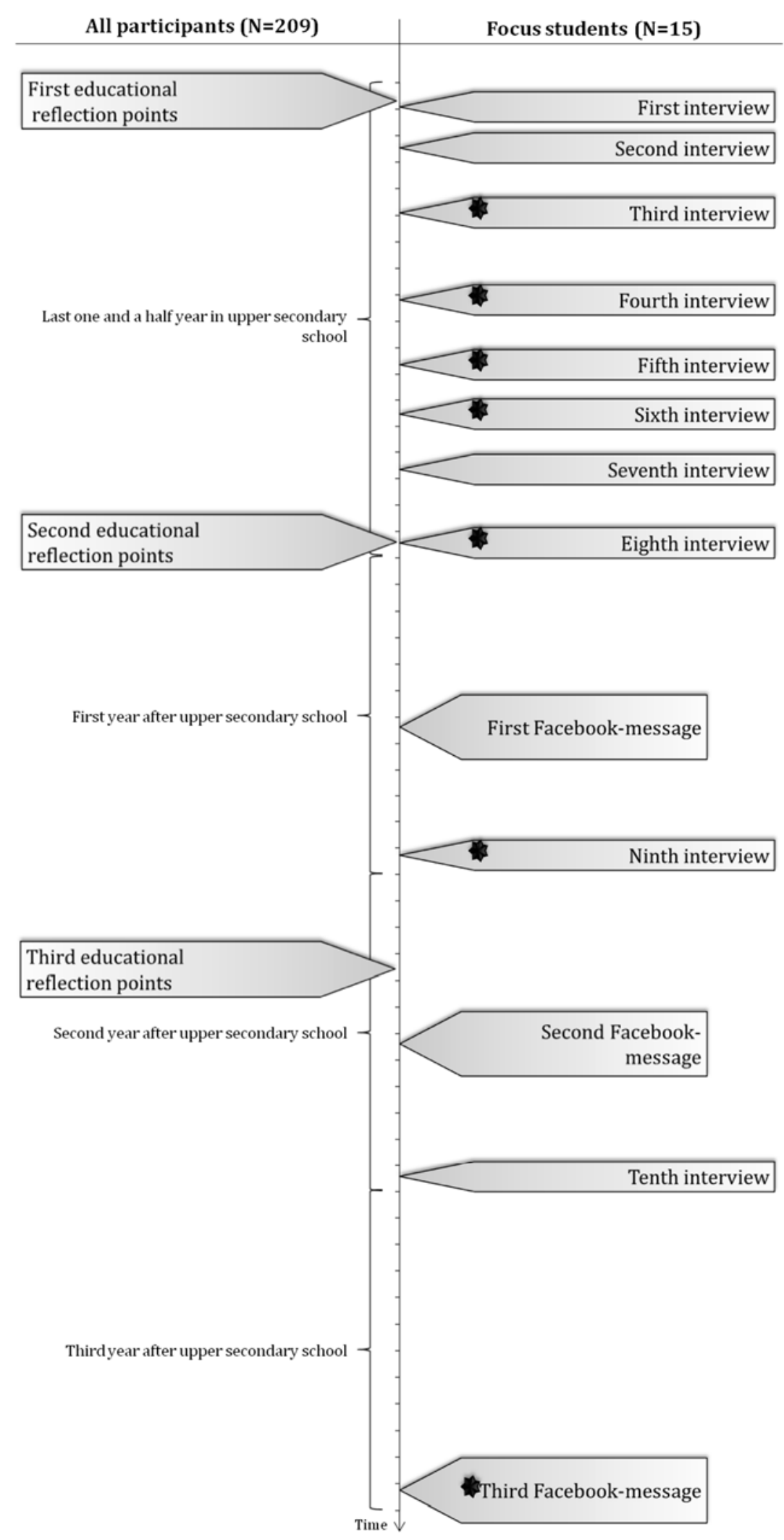

Figure 1: Design and time line. Data collection points for all project participants (left-hand side) and focus students (right-hand side). The stars indicate seven quantitative measurement points of focus students' motivation for pursuing specific educational trajectories. 
Lykkegaard \& Ulriksen - In and out of the STEM pipeline 


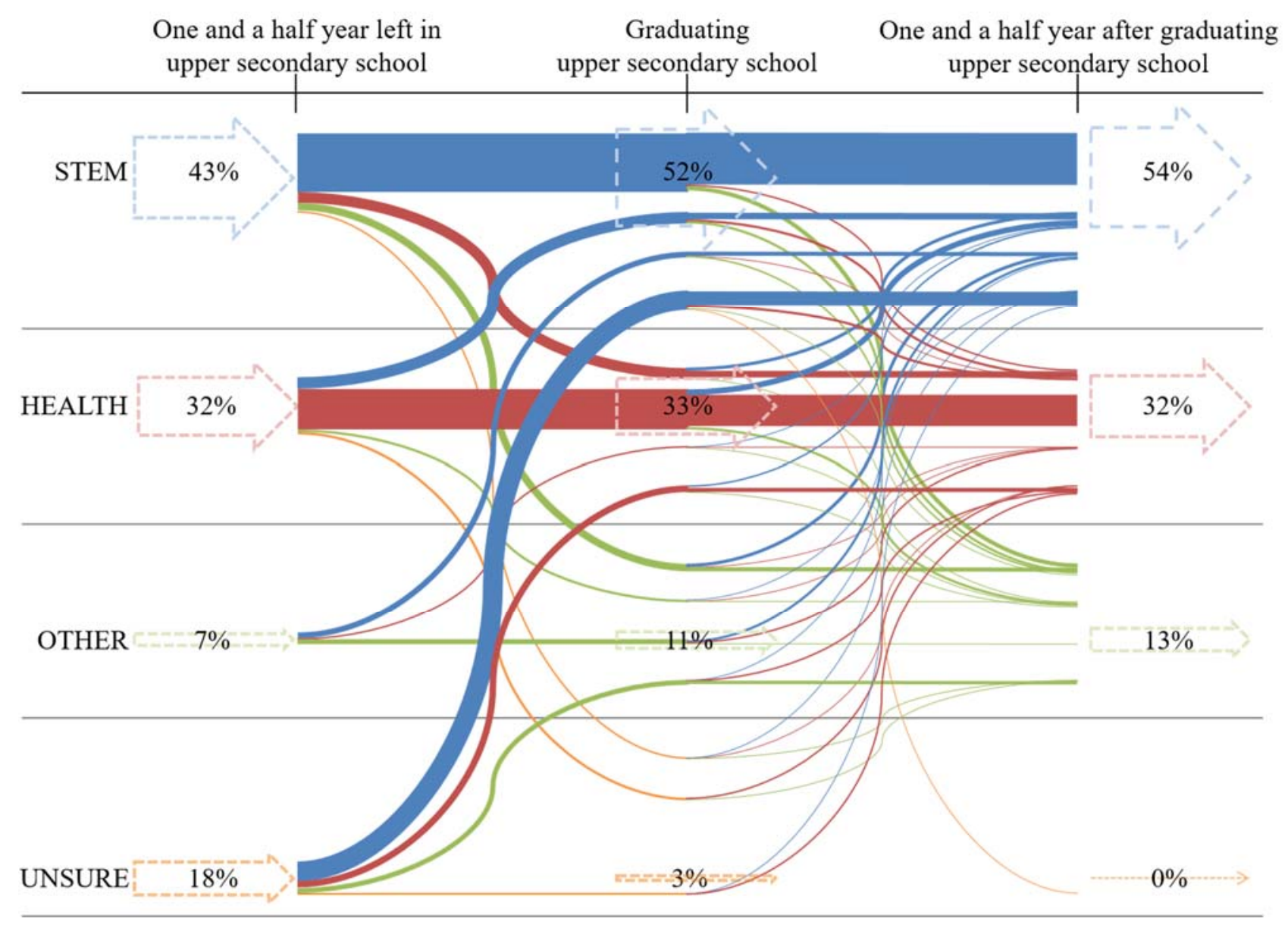

Figure 2: Participants' educational trajectories $(\mathrm{N}=209)$. The percentages and the width of the dotted-lined arrows indicate the share of students that at the particular reflection-point expressed the intention to pursue a programme within each group of programmes. 


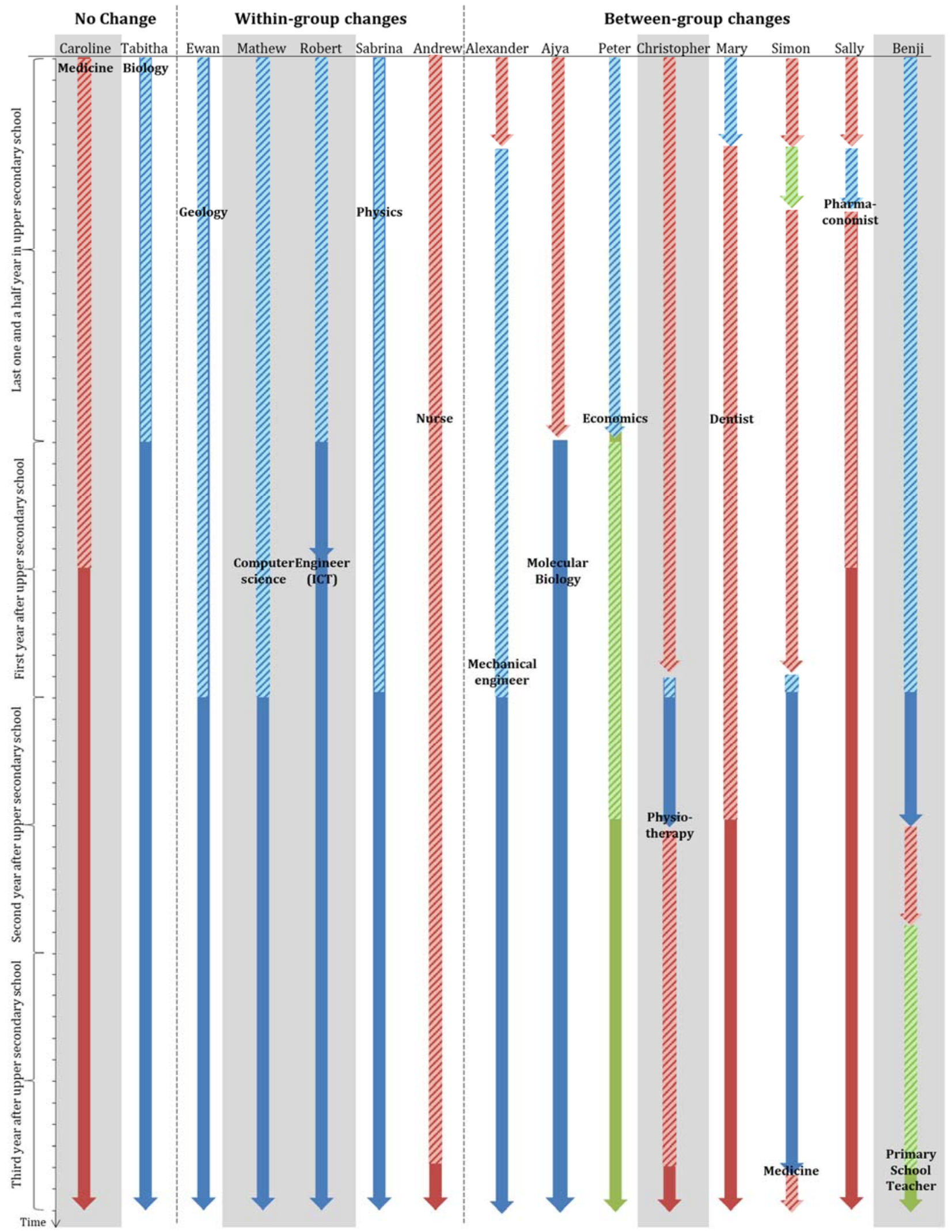

Figure 3: The 15 focus students' intended and actual educational trajectories

divided into 'no change', 'within-group changes' and 'between-group changes'. The 
students' educational trajectories are indicated by colour $($ STEM $=$ blue, HEALTH $=$ red, Other $=$ green). Each vertical arrow indicates one student's trajectory. The specific study programmes mentioned written on the vertical arrow in the figure indicate the first time students prioritised the specific trajectory they articulated expressed at the end of our study. Shaded arrows indicate intended trajectories and full-coloured arrows indicate actual study paths, i.e., study programmes students actually entered and in some cases left again. The five students with grey background are the case students presented in Figure 4-8. 


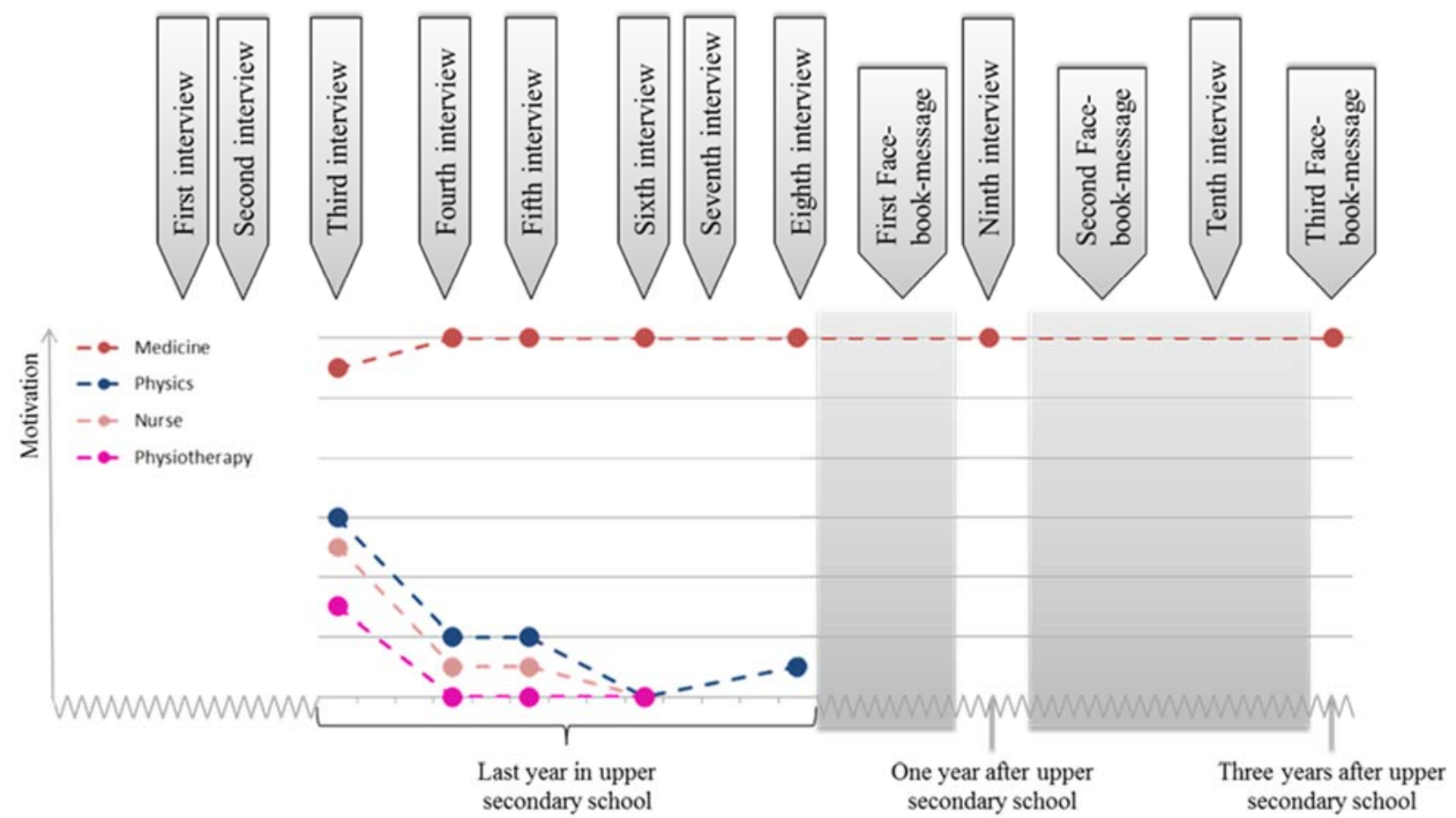

Figure 4: Caroline's educational trajectoryies. The horizontal lines refer to the seven point Likert-scale that indicates the level of motivation for pursuing a particular study trajectory. Coloured dashed lines connect successive survey responses for each intended or real educational trajectory. Dashed lines that cominge together in a single point illustrate equal motivation for several intended educational trajectories at that point in time (e.g. for physics, nurse and physiotherapy at the time of the sixth interview). The two grey-shaded areas compress a time period of one and two years respectively. 


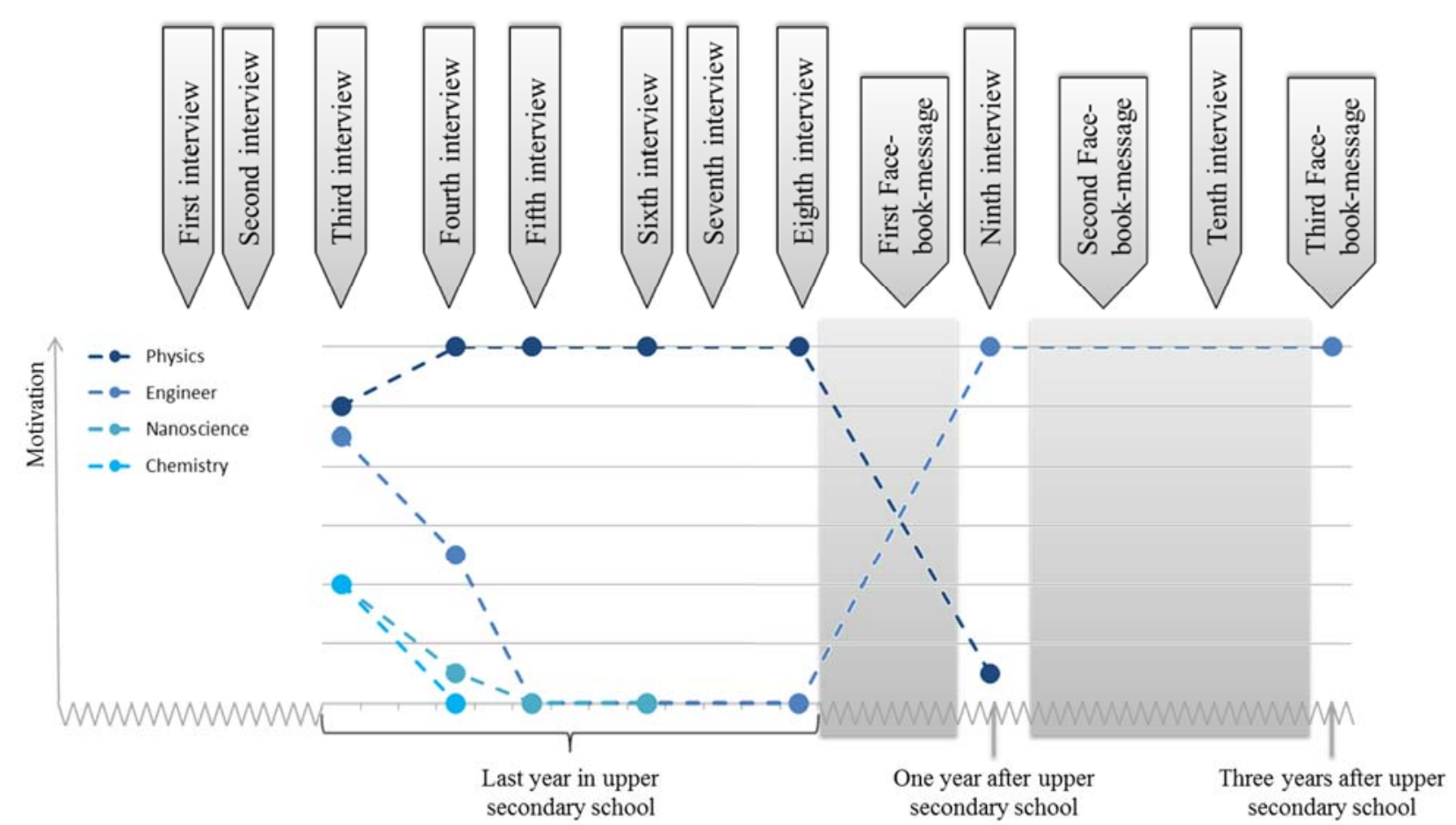

Figure 5: Robert's educational trajectoryies. The horizontal lines refer to the seven point Likert-scale that indicate the level of motivation for pursuing a particular study trajectory. The dashed lines connect successive survey responses for each educational trajectory. Dashed lines that cominge together in a single point illustrate equal motivation for several intended educational trajectories at that point in time (e.g. nanoscience and chemistry at third interview as well as engineer and nanoscience at fifth interview). The two grey-shaded areas compress a period of one and two years respectively. Robert initially wishes to study physics, but from the ninth interview, he is more motivated for engineering. 


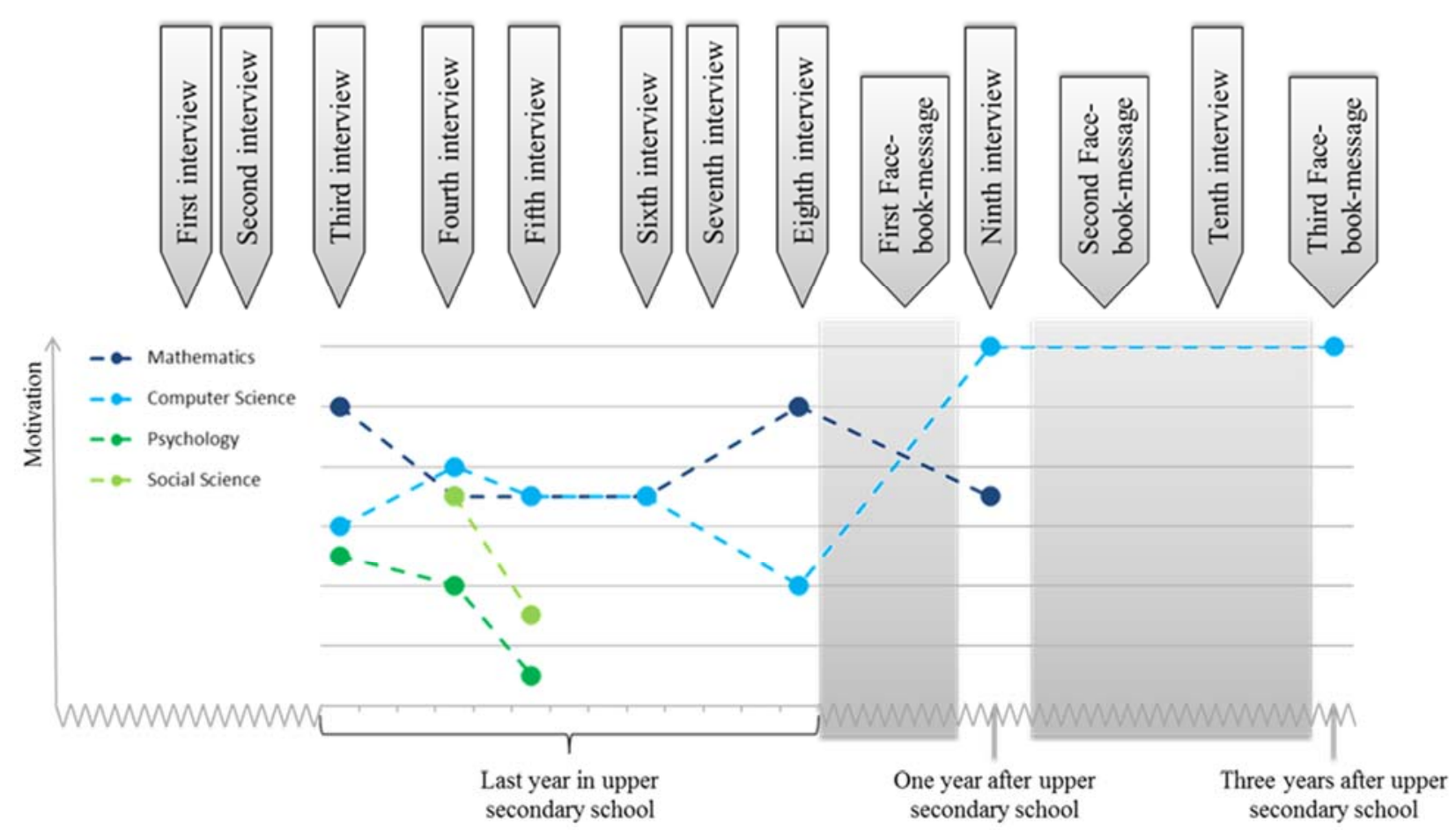

Figure 6: Mathew's educational trajectoryies. The horizontal lines refer to the seven-point Likert-scale that indicate the level of motivation for pursuing a particular study trajectory. The coloured dashed lines connect successive survey responses for each educational trajectory. Further description in Figure 4. 


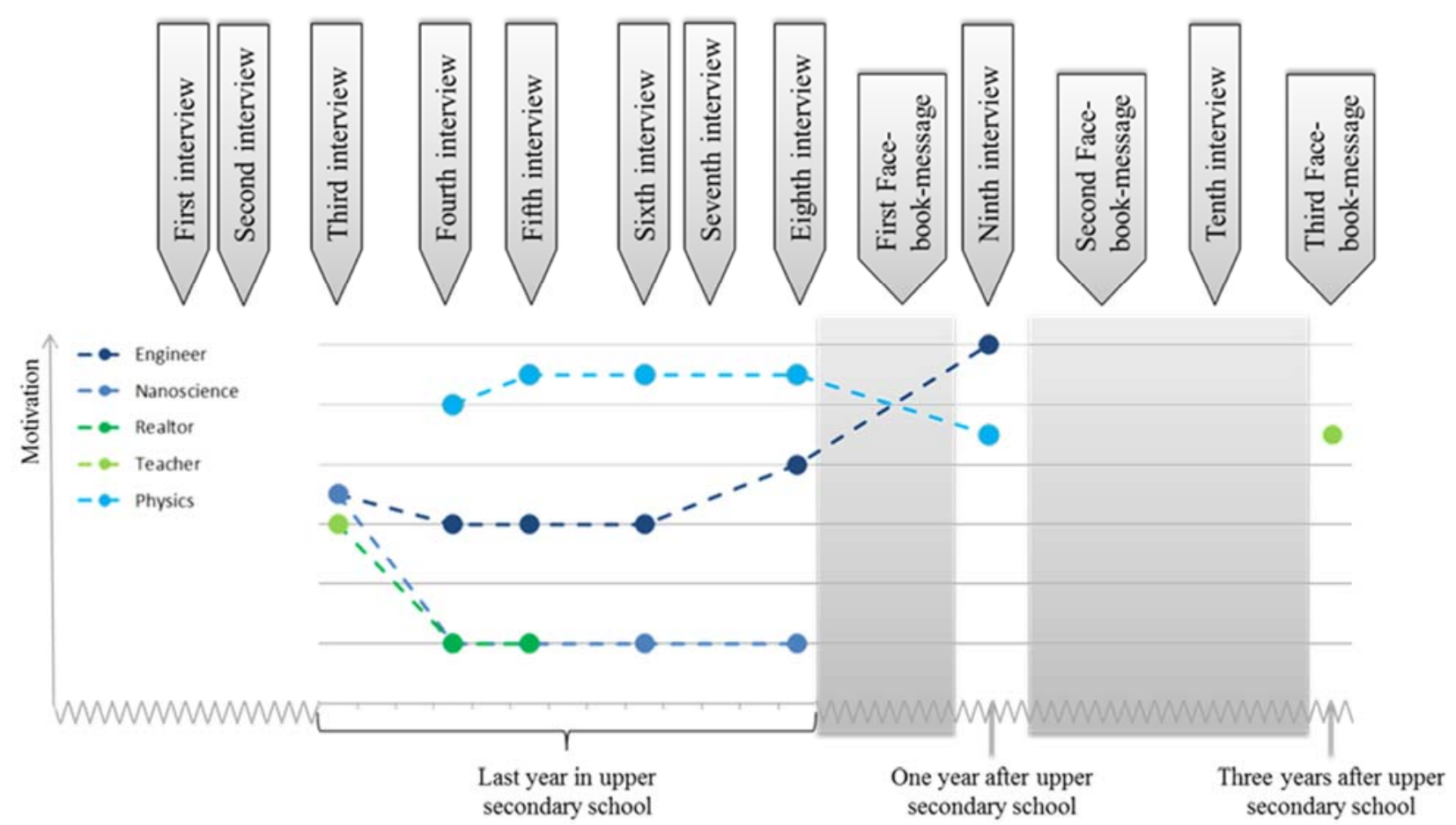

Figure 7: Benji's educational trajectoryies. The horizontal lines refer to the seven-point Likert-scale that indicate the level of motivation for pursuing a particular study trajectory. The coloured dashed lines connect successive survey responses for each intended or real educational trajectory. The dDashed lines coming together in a single point illustrate that Benji was equally motivated for nanoscience and engineer at third interview, for realtor and teacher also at third interview as well as for nanoscience and realtor at fourth and fifth interview. Benji only expressed a motivation for becoming a teacher at the third interview and the third Facebook-message. Therefore, not dashed line connects the two points. 

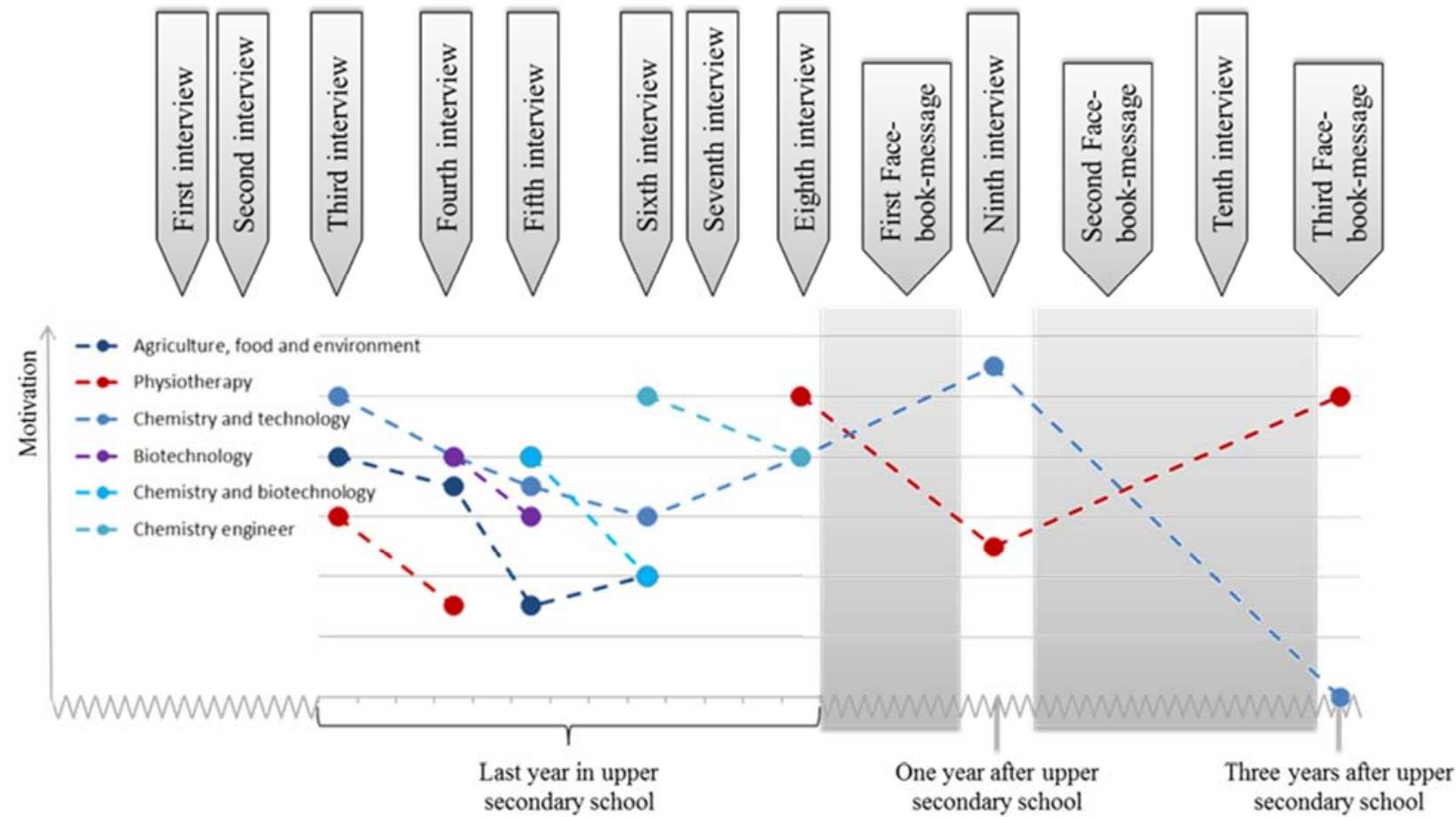

Figure 8: Christopher's educational trajectoryies. The horizontal lines refer to the seven-point Likert-scale that indicate the level of motivation for pursuing a particular study trajectory. The coloured dotted lines connect successive survey responses for each educational trajectory. Further description in Figure 4. 